\title{
Attributes of Travel Destinations that Influence Tourists' Decisions: A Systematic Review
}

\author{
Ortaleza, Maricar S. ${ }^{1}$ \\ Mangali, Glen R.*2 \\ Polytechnic College of the City of Meycauayan, Philippines ${ }^{1}$ \\ Colegio De San Juan De Letran, Philippines ${ }^{2}$
}

\begin{abstract}
Making decisions on where to travel may be very exhilarating for tourists but can be quite difficult when it comes to selecting what interesting places to visit and explore. There had been a number of published research studies that discussed travel destinations and influence tourists' decision but few journals synthesized these studies to guide experts make informed decision in travel and tourism industry. This research was intended to provide a systematic review of the attributes of travel destinations that influence tourists' decisions. This paper presented a classification of more than 50 review studies, published in various travel, tourism and hospitality books, articles, and journals listed in EBSCO, ProQuest, Research Gate, and Google Scholar. Using the PRISMA model, the research studies were screened, scrutinized and analyzed to identify and substantiate the attributes of a travel destination that influence tourists' decision. Results of the study showed that there are 5A's that attributes travel destination namely accommodation, articulated stories, affordability, accessibility, and attribution. The study provided an overview of the decision of tourists in choosing a travel destination and focused on the factors decision-making and destination. Furthermore, it serves as guides for business owners to know the deciding factors of tourists and make informed decision to make the business afloat and keep going. Keywords: Travel Destination, Tourists, Tourists' Decision, Accommodation, Business
\end{abstract}

\footnotetext{
*Corresponding author: Mangali, Glen R.; E-mail: glen.mangali@letran.edu.ph DOI: https://doi.org/10.37227/ITHJ-2021-03-247
}

\section{Introduction}

The essence of tourists' decision in choosing a destination is of much significance in determining the best places to go that links them to the critical aspects that may influence the decisionmaking (Lozanov, 2018). Tourism in Asia and the Association of Southeast Asian Nations (ASEAN) developed marketing strategies to augment tourist arrivals (TARR) from different parts of the world (Jariyachamsit, 2019). Each destination has its own qualities and amenities to offer. The attributes of a travel destination that may influence a tourist decision include accessibility, place, price, safety and security, and political stability (Jariyachamsit, Jannit, \& Praditpong, 2020). It was also mentioned that what influence 
decision-making include the condition of the place or destination quality, management and environment, transportation, safety and security, culture, likeness of the area, reason and cost of travel (Pooi, 2006).

The main idea of this review is to figure out the attributes of a travel destination that influence a tourist's decision. There were several researches that contribute to this field. However, only few studies identify the said variables of study. Specifically, this systematic review aimed to determine the preferences of tourists in choosing a travel destination. Comprehensive reviews on this study are quite few because decision-making process is multi-faceted and complex that are influenced by several factors affecting consumer behavior (Seyidov \& Adomaitiené, 2016). There were topics on tourism concepts that were reviewed individually (Guillet, Lee, Law \& Leung, 2011).

Choosing a travel destination is a complex process for tourists $(\mathrm{Ni}$, Tsao \& Wang, 2017). The results of this study could be a critical aspect in determining the significant aspects that influence tourists' selection of a place and an attraction (Dahiya \& Batra, 2016). Travel destinations that feature their attractions, image, price, amenities, accessibility, location attractiveness, comfort, safety and security, local cuisine, recreation, entertainment, souvenir shops, and human resources some of the aspects present in a travel destination that influence the decision of tourists (Seyidov \& Adomaitiené, 2016; Das, Sharma, Mohapatra \& Sarkar, 2007; Cho, 2008; Madhavan \& Rastogi, 2011; Khuong \& Nguyen, 2017; Zainali, Jafarpour, Hessam \& Zolghadr, 2014). Tourists have their own expectations by identifying certain features of a destination that attracts them and influence them in choosing a place including architecture, culture, food, landscape and shopping stores (Mirabent, 2019). Word of mouth that is taken affirmatively strongly affects tourist revisit intention which contributes to understanding the attributes of a travel destination (Singh \& Singh, 2019). Moreover, word of mouth influences the destination attribute that plays a crucial role in determining a tourist's choice for an attraction, satisfaction, and price (Mohammad, 2020).

There are six components in a travel destination that attract tourists including the type of accommodation, entertainment, food, tourism, and transportation that are often characterized by its accessibility, attraction, comfort, facilities, and conditions of mobility (Deng, Xu \& Wei, 2021). It is extremely important for destinations to constantly provide the highest standard in providing their services to address the tourists' needs and wants so that they could ensure their satisfaction (Camilleri, 2018).

Giving these attributes would provide decision makers of various tourism industries in different countries to plan and strategize their commitment in dealing with difficulties in the future and enhance destinations for better tourist preferences (Najafi, Raessi, Gorji, Ahmadi \& Haghighi, 2017).

\section{Research Methodology}

Applying the Preferred Reporting Items for Systematic Reviews (PRISMA) guidelines, the researcher searched from various databases such as EBSCO, ProQuest, ResearchGate, Google Scholar, using the terms "attributes of travel destinations", "influence of tourists" decisions", and "choosing a destination of tourists" (Siddaway, Wood \& Hedges, 2018). Manual search was also conducted. This captured the pertinent lists of needed articles for the entire review process that started from October 2020 to December 2020. The researcher applied the systematic review approach to establish accuracy and regulated process (Okoli, 2015). 
The selection process were collected from the electronic search results and were screened based on the title and abstract to determine the potential eligible articles and later on the researcher crossed-checked the initial results on the basis of attributes of tourist destinations influencing tourists' decisions. In searching for these categories, records should aim on identifying and enumerating the attributes that influence tourists deciding to travel to a certain destination.

Original research included systematic reviews, meta-analysis, peer-reviewed and academic journals, and paper presentations from conference proceedings. Several articles from the internet and tourism books were also included for additional data and clarifications. Commentaries and editorials were excluded. Only articles in English including those that were translated in the English language were included. All the articles were independently screened in complete full text to confirm eligibility.

The data collection methods include a data extraction form that was designed prior to data gathering. The researcher extracted study characteristics including the name/s of the author/s, year of publication, research title, research journal, volume, issue number, pages, research objective/s, key words or delineated factors, locus, method of study, and salient findings related to the factors influencing tourists' decisions.

The search strategy resulted in 1,948 citations. After screening the titles, there were only 211 articles left related to the variables under study, 93 did not refer to the aspects that influence tourists, 57 did not refer to tourists' decision-making, and 11 did not involve tourists. The remaining 50 references covered the variables that were related to the travel destinations that influence tourists' decision. After analyzing these aspects, the most notable approach in each case were noted.

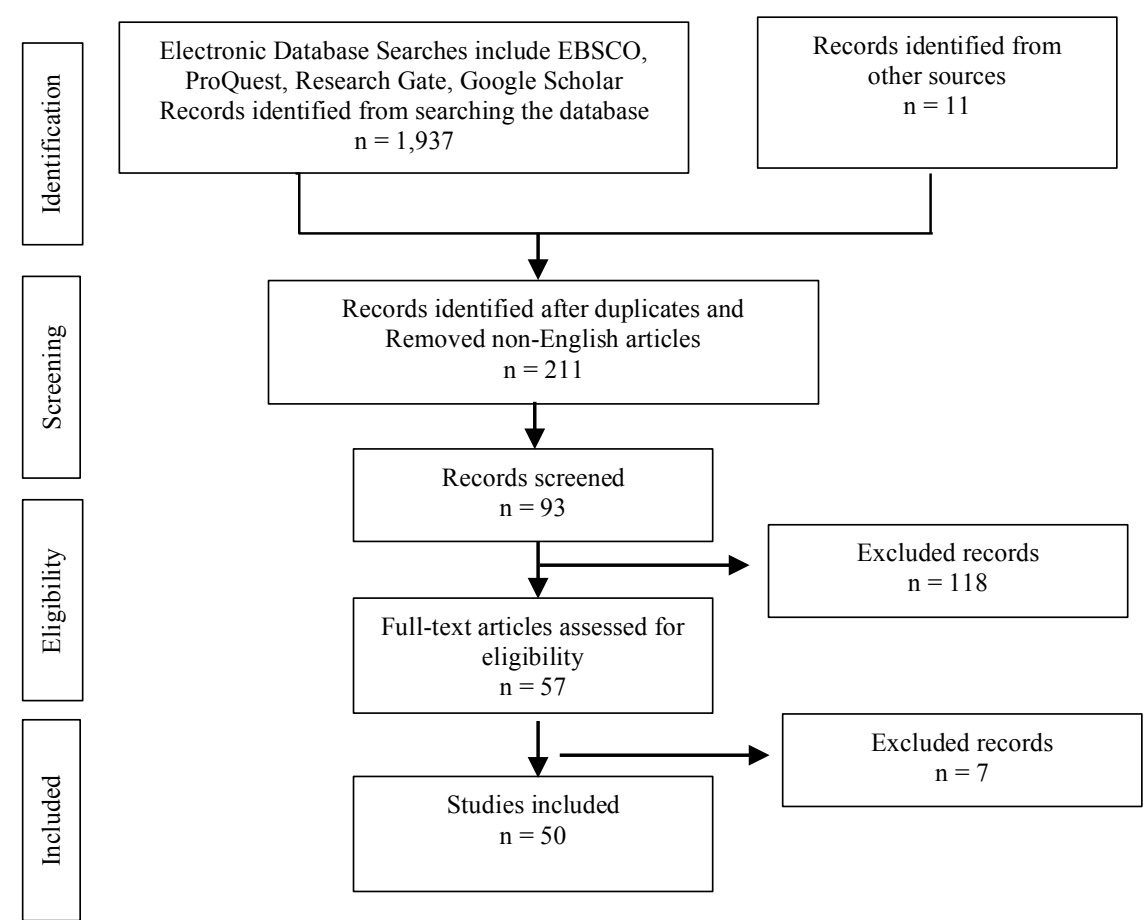

Figure 1: Diagram for the Study 


\section{Results and Analysis}

This section described and explained the different variables involved in the attributes of a travel destination that influence tourists' decisions according to various literature studied in tourism, hospitality, and management.

Following the results in the study of authors Kijima, Novani, Widiana, Palumian, and Cintyawati (2020), it was decided that in this research, the attributes of travel destinations that influence tourists' decision can be divided in five aspects or 5 A's including accommodation, articulated stories, affordability, accessibility, and attribution. Each variable that influence tourists' decision was described.

\section{Accommodation (Hotels and Restaurants)}

Accommodation is one of the most important aspects for people traveling when they spend overnight stay and dine outside their usual abode (Westscott, 2019). The variables related to accommodation include hotel, restaurant, service of hotel, and quality of service in restaurant including the variety of foods offered in the menu (Kijima, et. al., 2020 \& Gunasekaran and Anandkunar, 2012). Hotels and accommodation are both important in promoting tourism because they play a significant role in making a tourist destination popular (Ahiya, 2010). The quality and quantity of accommodation directly influence the totality of a successful tourist destination (Sharpley, 2000). Aside from the quality, affordable and budget friendly supplementary accommodations can directly and indirectly influence a guest's purchase and choice (Poudel, 2013). Choosing a place to stay especially in hotels is a complex task for guests. Tourists' decision are influenced by reviews done online or online assessments, Search Engine Optimization (SEO), Online Travel Agent (OTA), and many more. These factors influence the final decision in choosing a hotel accommodation (Pantelic, 2017).

Primary findings reveal that the location of a budget hotel, cleanliness, comfort, hotel staff services, maintenance, food and beverage and value for money of room rates are among the significant factors that influence tourists (Samy, 2016). Other findings say that the quality of services and facilities in a hotel, quality customer service of staff, hotel safety and security, and clean rooms influence customer's choice in choosing an accommodation (Peace, 2018).

\section{Articulated Stories}

Articulated stories or the so called word of mouth (WOM) is another significant part of promoting a destination and of equal importance when influencing tourists (Jalilvand \& Samiei, 2012). It is an essential element of promotion especially if the message and delivery are strong (Sweeny, Soutor \& Mazzarol, 2008). WOM has an impact to the decision-making of tourists after an experience on a trip (Harris, 2014). One of the most important sources of information when purchasing a travel package is through articulated stories online shared mostly by bloggers and vloggers. These travel experiences shared online makes a huge impact on the electronic word-of-mouth tourism and hospitality that helps in marketing a destination and consequently making part of the influence in making a decision (Litvin, Goldsmith \& Pan, 2008). It plays as a mediating role in influencing the perceived image of a place to the tourist's intention of choosing a destination $(\mathrm{Xu}, \mathrm{Niu} \&$ $\mathrm{Li}, 2020)$. The intention of purchasing a tourist product is distinctively influenced by so many travel experiences passed on from one tourist to another (Chen \& Chen, 2018). Electronic word of mouth is effective to tourists because they usually surf the internet before planning and deciding their next destination (Kijima et. al., 2020). 
Studies show that tourists are continuously more influenced on comments and opinions of friends and relatives when arranging a travel and choosing a destination than those who just simply surf the internet. One of the most comprehensive channels where tourists gather information are travel blogs, travel destination websites, travel vlogs, and other travel social networking sites (Mendez, Leiva \& Fernandez, 2012). In the study of Hao (2017), it was found out that word of mouth and destination image have an impact in decision-making of tourists. A study disclosed, that the image of a destination and electronic word-of-mouth have direct influence on tourist loyalty and directly affects their intention to visit (Kanwel, Lingqiang, Asif, Hwang, Hussain \& Jameel, 2019). Studies show that destinations which offer high quality of service would lead to repeat visitors because they eventually share their unforgettable experiences with friends and acquaintances (Çelik, Yüsbaşioğlu \& Topsakal, 2017). Tourists tend to revisit a destination if they are satisfied in the attractiveness of culture and high quality of service accommodation (Viet, Dang \& Nguyen, 2020).

\section{Accessibility}

In 2019, the United Nations World Tourism Organization (UNWTO) and ONCE Foundation launched the Accessible Tourism Destination (ATD) to boost the accessibility in tourist destinations. Accessibility pertains to tourism products, services, and facilities that do not only focus on human rights but also to equip destinations with business opportunities, to accept all guests and to augment their revenues (APEC, 2003).

In the study of Zeng \& He (2018), one of the factors influencing tourist flow is transportation meaning transportation expense and network. Road quality and infrastructure are very much of great influence on travel because a modernized road network leads to increase traffic flow that boosts the number of passengers and tourists in a destination (Mazrekaj, 2020). Public transportation plays a vital role in a destination's accessibility. It is a key factor to note that ease of access, an existing and effective public transportation connects more tourist flows (Yang, Li \& Li, 2017). Public transport that includes travel time, comfort, and trip length of passengers are also vital in determining customer satisfaction (Hansson, Pettersson, Svensson \& Wretstrand, 2019).

\section{Affordability}

The fourth aspect that influence tourists' decision is affordability. It includes local people's hospitality, cleanliness, safety and security, affordability near a tourist attraction, and affordable food and beverage (Kijima, et.al., 2020).

There are five A's of tourism that include Attraction, Activities, Accessibility, Accommodation, and Amenities. However, there is a sixth ' $A$ ' that is equally important in influencing tourists to a destination and that is Affordability. Affordable tourism destination such as cost of travel, rates of accommodation, and entrance fees to attractions would definitely help in making a successful destination (Samuel, 2020). One of the studies show that most of the customers believe that online hotel booking is convenient, more reliable, faster, and cheaper than booking offline (Teng, Wu \& Chou, 2020). In the study of Chen, Tsai, and Chiu (2015), it was found that price is a significant factor in choosing hotels even of low quality. Khuong and Nyuyen (2017) considered the perceived price as a factor of a destination choice. Xiang (2013) described Chinese tourists as frugal, hedonistic and mixed tourists so it is important to consider affordability of tourism products. Perceived affordability and availability of personal finances encourage tourists to 
spend more. Affordability significantly increased in the Traveller Sentiment Index (TSI) according to Kandzavelou (2015).

Aside from the attractiveness of a destination, people related factors like local residents who are tourists friendly can make the destination remain attractive to visitors (Vengesayi, Mavondo \& Reisinger, 2009). The results in Udoh's (2019) study revealed that the hospitality of people can influence attraction in a tourist destination.

Cleanliness is another attribute to consider that should be considered in a tourist destination because unclean destinations can have a negative impact on tourist satisfaction (Hasugian, Sukarta \& Syafariani, 2016).

Cost of stay in a tourist establishment includes the price of accommodation, food and beverage ( $\mathrm{F} \& \mathrm{~B})$, transportation, products, and services. If the cost of stay increases, chances are tourist satisfaction may decrease (Suanmali, 2014).

Safety and security are both important that have become main aspects influencing security issues and a passive factor as an element of tourism with the act of protecting tourists and their belongings during the trip (Kővári \& Zimányi, 2011).

\section{Attribution}

Attribution includes the existence of souvenir shops and local events or ceremonies (Kijima, et.al., 2020). Studies show that brand-related attributions influence satisfaction. Pleasure and place attachments enhance effects of a tourism experience as well (Orth, et al., 2012).

Souvenir shopping is another important part of a travel package that may characterize the totality of a travel experience (Kong \& Chang, 2016). Shopping for tourists is an essential activity because a trip is not complete without buying souvenirs or anything from a destination (Yuksel, 2004). Chinese that are categorized as hedonistic tourists purchase multiple souvenirs (Xiang, 2013). Shopping tourism can also be considered as a competitive factor in influencing tourists in choosing a destination (Silva, Breda, Brandão, Costa \& Costa, 2019). In the study of Zainali, Jafarpour, Hessam \& Zolghadr (2014), shopping experience is considered as part of tourist satisfaction where tourists' level of satisfaction lies on the stores or souvenir shops. Shopping may not be a major reason for travel but it can be a motivator for a tourist to go to a place that offers enjoyable buying experience in certain destinations (Azmi, Ahmad, Abdullah \& Shaw, 2019).

Events and event destination also plays an important role in establishing a destination attraction because a successful event leads to greater visitor satisfaction and loyalty that leads to repeat events and tourists (Oklobdžija, 2015).

\section{Conclusion and Implication of the Study}

There are plenty of researches related to tourists and tourism but the variables that encompasses the attributes of a travel destination that influence tourists' decision is quite few. There is a series of variables that influence the decision of tourists in choosing a destination. These variables are classified into accommodation, articulated stories, accessibility, affordability, and attribution. According to the literatures studied, one of the aspects that influence tourists' decision is accommodation that includes hotels and restaurants. This is because it is considered as one of the most important attributes in any destination may they be big or small, luxurious or simple, expensive or cheap. A place to stay overnight or more is quite significant for the traveler's safety and can enrich the 
overall experience in the destination. The role of accommodation surely influences a tourist's decision.

With respect to another variable 'articulated stories' or the so called 'word of mouth', it is a significant attribute in influencing tourists to make decisions because this variable spreads very fast and directly affects decision-making based on the quality of tourism experience. This experience is a great aspect to convince or influence other tourists in visiting a destination.

The variable 'accessibility' influences tourists because road quality and infrastructure including the means of transporting tourists from one place to another has an effect on tourists' experience and overall quality of stay. Availability of public transportation to all kinds of tourists, whether physically able or not, is an important factor to enable to reach the intended place of attraction and enjoy the experiences in the destination.

The other variables 'affordability' and 'attribution' are definitely attributes to consider in influencing tourists' decision. Affordability may be a contrast to convenience because it may pay a higher price considering a more convenient and luxurious trip. Attribution that is related to availability of souvenir shops is a special part of a trip. Buying souvenir items make tangible items intangible brought by memories of the tourist destination.

\section{Limitations and Directions for Future Research}

This research is delimited to the attributes of travel destinations that influence tourists' decisions during the COVID pre-pandemic period. Future lines of study will attempt to determine if these variables are still true and how it will affect the expenditure of tourists in these destinations and the country's GDG amidst the current pandemic situation. It would be interesting to explore on the attributes of travel destinations that influence tourists' decisions during pandemic and post-pandemic period. It is recommended to explore the different attributes of tourist's decision based on geographical location and region to assists and guide business owners, strategize and predict plan intervention that benefit domestic and international tourism industry of various countries.

\section{References}

Azmi, A., Ahmad, M. A., Abdullah, A., \& Shaw, G. (2019). Shopping in Malaysia. A study of international tourists' experience and expectation. International Journal of Innovation, Creativity and Change, 8(4), 199-212.

Camilleri, M. A. (2018), "The tourism industry: an overview", in Travel Marketing, Tourism Economics and the Hotel Product, Springer Nature, Switzerland, pp. 3-27.

Çelik, P., Yüsbaşioğlu, N., \& Topsakal, Y. (2017). “The impact of tourists' perception on revisit intention", in proceedings book in international tourism congress 2017 in Peniche, 2017, Portugal, pp. 745-752.

Chen, M. \& Chen, J. (2018), "Effects of internet word-of-mouth of a tourism destination on consumer purchase intention: based on temporal distance and social distance", in $\mathrm{Xu}, \mathrm{J}$, Gen, M., Hajiyev, A., Cooke, F. (Eds.), proceedings of the eleventh international conference on management science and engineering management 2017, in Kanazawa, Springer Cham, Japan, pp. 321-330.

Chen, C. M., Tsai, Y. C., \& Chiu, H. H. (2015). The decision-making process of and the decisive factors in accommodation choice. Current Issues in Tourism, 20(2), 111-119. 
Cho, V. (2008). Linking location attractiveness and tourist intention. Tourism and Hospitality Research, 8(3), 220-224.

Das, D., Sharma, S. K., Mohapatra, P. K. J., \& Sarkar, A. (2007). Factors influencing the attractiveness of a tourist destination: a case study. Journal of Services Research, 7(1), 103-134.

Deng, B., Xu, J., \& Wei, X. (2021). Tourism destination preference prediction based on edge computing. Hindawi Journal, 2021, 1-11.

Dahiya, K. S. \& Batra, D. K. (2016). Tourist decision-making: Exploring the destination criteria. Asian Journal of Management Research, 7(2), 140-153.

Guillet, B. D., Lee, A., Law, R., \& Leung, R. (2011). Factors affecting outbound tourists' destination choice: the case of Hong Kong. Journal of Travel and Tourism Marketing, 28(5), 556-566.

Gunasekaran, N. \& Anandkumar, V. (2012). Factors of influence in choosing alternative accommodation: a study with reference to Pondicherry a coastal heritage town. Science Direct, 62, 1127-1132.

Hao, L. (2017). The impact of destination image and words of mouth on Chinese tourists' destination to visit Thailand. Bangkok University Research.

Hansson, J. Pettersson, F., Svensson, H., \& Wretstrand, A. (2019). Preferences in regional public transport: a literature review, European Transport Research Review, 11(38).

Harris, A. (2014). "Word of mouth in tourism: Reflections and directions-A review of word-ofmouth in tourism research", in Tourism and hospitality in the contemporary world: trends, changes and complexity council for Australasian tourism and hospitality education, in Brisbane, 2014, Australia.

Hasugian, L. P., Sukarta, S., \& Syafariani, F. (2016), "Information system of environment cleanliness governance at Indonesia" (Case study: Ijen Crater, Banyuwangi), in $1^{\text {st }}$ Conference on Interdisciplinary Academic Research and Innovation, Badung, 2016, Indonesia.

Jariyachamsit, S. (2019). "Factors influencing Asian tourists' decision in selecting Bangkok as their travel destination", in ICBTS 2019 International Academic Multidisciplines Research Conference, in Copenhagen.

Jariyachamsit, S., Jannit J., \& Praditpong, P. (2020). "Factors influencing travel decision on cultural tourism of Thai tourists, travelling to Samut Sungkhram province", in ICBTS 2020 International Academic Multidisciplinary Research Conference, in Cape Town.

Kandzavelou, V. (2015). "Perceived 'affordability' of travel encourages travelers to spend more", Travel Daily News, 20 May.

Kanwel, S., Lingquiang, Z., Asif, M., Hwang, J., Hussain, A., \& Jammel A. (2019). The influence of destination image on tourist loyalty and intention to visit: testing a multiple mediation approach, Sustainability Journal, 11(22), 1-19.

Khuong, M. N. \& Nyuyen, P. A. (2017). Factors affecting tourist destination satisfaction and return intention - a study in Ho Chi Minh City, Vietnam. Journal of Economic, Business and Management, 5(2).

Kijima, K., Novani, S., Widiana, R., Palumian, Y., \& Cintuawati, C. (2020). What influences tourists' visit decision to coastal area? a lesson learned from southern beaches of West Java. The Asian Journal of Technology Management, 13(1), 63-81.

Kong, W. H. \& Chang, T. (2016). Souvenir shopping, tourist motivation, and travel experience. Journal of Quality Assurance in Hospitality \& Tourism, 17(2), 163-177.

Kövári, I. \& Zimányi, K. (2011). Safety and security in the age of global tourism (the changing role and conception of safety and security in tourism). Research in Agriculture and Applied Economics, 3-4(5), 59-61.

Litvin, S. W., Goldsmith, R. E., \& Pan, B. (2008). Electronic word-of-mouth in hospitality and tourism management. Tourism Management, 29(3), 458-468. 
Lozanov, P. (2018). What are the major factors influencing travelers to book their next trip? Medium. Retrieved November 14, 2020, from https://medium.com/15togo/what-are-themajor-factors-influencing-travelers-to-make-a-booking-100918c6156

Madhavan, H. \& Rastogi, R. (2011). Social and psychological factors influencing destination preferences of domestic tourists in India. Taylor \& Francis Online, 32(2), 207-217.

Mazrejah, R. (2020). Impact of road infrastructure on tourism development in Kosovo. International Journal of Management, 11(4), 466-474.

Mirabent, S. V. (2019). European urban destinations' attractors at the frontier between competitiveness and unique destination image: a benchmark study of communication practices. Journal of Destination Marketing \& Management, 12(17), 37-45.

Mendez, J. H., Leiva, F. M., \& Fernandez, J. S. (2012). The influence of e-word-of-mouth on travel decision-making: consumer profiles. Current Issues in Tourism, 18(11), 1001-1021.

Mohammad, B. A. A. (2020). The effect of word of mouth and destination attributes on travel intention to Jordan. Journal of Tourism \& Hospitality 9(6), 1-10.

Najafi, B., Raessi, P., Gorji, H.A., Ahrnadi, A., \& Haghighi, M. (2017). Identifying factors affecting destination choice of medical tourists: a systematic review of literature. Journal of Fundamental and Applied Science, 9(2S), 1309-1328.

Ni, C., Tsao, C., \& Wang Y. (2017). "The international decision-making and travel behavior of graduates participating in working holiday", in Butowski, L. (Ed.), Mobilities, Tourism and Travel Behavior: Contexts and Boundaries, IntechOpen.

Oklobdžija, S. (2015). The role of event in tourism development. BizInfo Journal, 6(2), 83-97.

Okoli, C. (2015). Guide to conducting a standalone systematic literature review. Communications of the Association for Information Systems, 37(43), 879-910.

Orth, U. R., et al., (2012). Using attribution theory to explain tourists' attachments to place-based brands. Journal of Business Research, 65(9), 1321-1327.

Pantelic, V. (2017). Factors influencing hotel selection: decision making process. Research Gate. https://www.researchgate.net/publication/333356298

Peace, M. (2018). Assessment of the factors influencing consumer choice of accommodation facilities in Kampala Central Division. [Undergraduate Dissertation, Makerere University]. Makarere University Undergraduate Dissertations Repository.

Pooi, A. L. (2006). Factors influencing international tourists in choosing a travel destination: a case study of Penang, Malaysia. International Journal of Tourism Cities, 3(3), 00-00.

Reza Jalilvand, M. \& Samiei, N. (2012). The effect of word of mouth on inbound tourists' decision for traveling to Islamic destinations (the case of Istahan as a tourist destination in Iran), Journal of Islamic Marketing, 3(1), 12-21.

Samuel, P. (2021, June 21). "What are the 5A's of tourism?" Color Whistle. Retrieved November 14, 2020, from https://colorwhistle.com/travel-tourism-components/

Samy, H. (2016). Exploring factors that influence domestic tourists' satisfaction with budget hotel services in Egypt, Journal of Tourism, Heritage \& Services Marketing, 2(2), 17-22.

Seyidov, J. \& Adomaitienè, R. (2016). Factors influencing local tourists' decision-making on choosing a destination: a case of Azerbaijan. Ekonomika, 95(3).

Siddaway, A. P., Wood, A. M., \& Hedges, L. V. (2018). How to do a systematic review: a best practice guide for conducting and reporting narrative review, meta-analysis, and metasynthesis, Annual Review of Psychology, 70, 747-770.

Silva, R., Breda, Z., Brandão, F., Costa, R., \& Costa, C. (2019). Shopping tourism: a destination management perspective, in Rocha, Á., Abreu, A., de Carvalho, J. Liberato, D. Gonzalez, E. Liberato, P. (Eds.), Advances in Tourism, Technology and Smart Systems, Smart Innovation, Systems and Technologies, 171. Springer, Singapore.

Singh, R. \& Singh, J. (2019). Destination attributes to measure tourist revisit intention: a scale development. SAGE Journals, 20(2), 549-572.

Sweeny, J. C., Soutor, G., \& Mazzarol, T. (2008). Factors influencing word-of-mouth effectiveness: receiver perspectives. SAGE Journals, 42(3/4), 334-364. 
Suanmali, S. (2014). "Factors affecting tourist satisfaction: An empirical study in the northern part of Thailand", in $4^{\text {th }}$ International Conference on Tourism Research in 2014, in Sabah, Malaysia.

Teng, Y., Wu, K., \& Chou, C. (2020). Price or convenience: what is more important for online and offline bookings? a study of a five-star resort hotel in Taiwan. Sustainability, 12(10), 3972.

Udoh, I.S. (2019). Hospitality of the people at the tourism destination and destination attractiveness of Akwa Ibon State, Nigeria. International Journal of Research in Tourism and Hospitality, 5(2), 1-7.

Vengesayi, S., Mavondo, F., \& Reisinger, Y. (2009). Tourism destination attractiveness: Attractions, facilities and people as predictors. Tourism Analysis, 14(5), 621-636.

Viet, B. N., Dang, H. P., \& Nguyen, H. H. (2020). Revisit intention and satisfaction: The role of destination image, perceived risk, and cultural contact. Cogent Business \& Management, $7(1)$.

Westscott, M. (Ed.). (2019). Introduction to tourism and hospitality in B.C. Victoria $-2^{\text {nd }}$ Edition. Creative Commons Attribution, Canada.

Xiang, Y. (2013). The characteristics of independent Chinese outbound tourists. Tourism Planning and Development, 10(2), 134-148.

Xu, F., Niu, W., \& Li, S. (2020). The mechanism of word-of-mouth for tourist destinations in crisis. SAGE Journals, 10(2).

Yang, Y., Li, D., \& Li, X. (2017). Public transport connectivity and intercity tourist flows. Journal of Travel Research, 58(1), 25-41.

Yuksel, A. (2004). Shopping experience evaluation: A case of domestic and international visitors. Tourism Management, 25(6), 751-759.

Zeinali, B., Jafarpour, M., Hessam, A., \& Zolghadr, H. (2014). Tourists' satisfaction with shopping experience: a socio-demographic analysis. International Journal of Academic Research in Business and Social Sciences, 4(6).

Zeng, B. \& He, Y. (2018). Factors influencing Chinese tourist flow in Japan - a grounded approach. Asia Pacific Journal of Tourism Research, 21(1), 56-69. 